\title{
The great NHS debate
}

\author{
Elizabeth Loder head of research
}

The BMJ

In recent days The $B M J$ has been filled with commentary and debate about the future of the NHS. NHS England's updated delivery plan calls for many changes in the way healthcare is provided and the priority attached to specific services. Without extra money, this is a zero sum game. More resources devoted to integrated care, extended hours for GPs, and improved mental health and cancer services mean fewer resources for other things. For example, the 18 week waiting time target for elective surgery has been abandoned (doi:10.1136/bmj.j1652).

A House of Lords inquiry into NHS sustainability concludes that a plan of some sort is needed (doi:10.1136/bmj.j1713). The report condemns the "short sightedness of successive governments" for failing to plan effectively for the long term future of NHS and adult social care funding. A tax funded NHS, free at the point of use, is "the most efficient way of delivering health care, and should remain in place now and in the future." But the report warns that many aspects of healthcare delivery will have to change if this is to remain the case.

Reaction is mixed to the changes recommended in this latest delivery plan. Editorialist Chris Ham applauds the plan for its "bold ambition" to introduce integrated accountable care systems (doi:10.1136/bmj.j1678). If anything, Ham says, the delivery plan is too cautious for proposing the systems in only nine areas of England and not the whole country. He admires the fact that it does not assume additional funding and instead acknowledges "the inevitability of hard choices."

Others take a more sceptical view. Mark Porter, the BMA's chair of council, has called the efficiency targets "fanciful"
(http://bit.ly/2nYz32R). The idea that every emergency department will provide GP triage by next Christmas strikes Margaret McCartney as misguided (doi:10.1136/bmj.j1655). GPs, she says, are needed in their own clinics, not emergency departments, where "they won't be able to offer continuity of care, the special magic ingredient of general practice." Then too, "How do we know they will help?" McCartney put this question to NHS England and was told there is "nothing published on that yet."

Meanwhile, Hugh Alderwick and Chris Ham have studied the 44 sustainability and transformation plans (STPs) published by local authorities (doi:10.1136/bmj.j1541). These describe how the Five Year Forward View will be delivered at the community level. Common themes emerge, including commitments to improve IT and strengthen preventive and early intervention programmes. Alderwick and Ham outline barriers to implementation, including the fact that plans were developed with varying levels of public and patient involvement and contain much jargon and technical language.

Maurice Saatchi, Paul Buchanan, and Nigel Crisp debate whether something more drastic, a royal commission on the NHS, is needed (doi:10.1136/bmj.j1621). An independent public inquiry at the highest level would allow important questions to be asked and answered, Saatchi and Buchanan say. But Crisp says that having healthcare workers give evidence to a judge won't solve anything. A better option, he says, would be a bottom-up approach that involves people who work in healthcare in its redesign. 